\title{
Corrigendum
}

\section{Corrigendum to "Fluorescence evaluations for porphyrin formation during topical PDT using ALA and methyl-ALA mixtures in pig skin models" [Photodiagn. Photodyn. Ther. 15 (2016) 236-244]}

\section{Alessandra Keiko Lima Fujita ${ }^{a}, *$, Phamilla Gracielli Sousa Rodrigues ${ }^{a}$,} Michelle Barreto Requena ${ }^{\mathrm{a}}$, André Escobar ${ }^{\mathrm{b}}$, Rozana Wendler da Rocha ${ }^{\mathrm{b}}$, Andrigo Barboza de Nardi ${ }^{b}$, Cristina Kurachi ${ }^{a}$, Priscila Fernanda Campos de Menezes ${ }^{a}$, Vanderlei S. Bagnato ${ }^{a}$

a São Carlos Institute of Physics, University of São Paulo, P.O. Box 13560-970, Sao Carlos, SP, Brazil

${ }^{\mathrm{b}}$ Department of Veterinary Clinic and Surgery, Faculty of Agriculture and Veterinary Sciences, São Paulo State University (UNESP), Jaboticabal, SP, Brazil

The authors regret to inform that on Fig. 9, the $\mathrm{x}$ and $\mathrm{y}$ axis values were called out incorrectly in Portuguese language for all six graphs. The correct axis names, for all six graphs in the figure, are [Depth ( $\mathrm{mm})$ ], and [Fluorescence intensity profile (a.u)] for the $\mathrm{x}$ and $\mathrm{y}$ axis, respectively. Also, the arbitrary units scale in the y axis has been changed to reflect a maximum of 1.0.

The authors sincerely apologize for any inconvenience caused.

DOI of original article: http://dx.doi.org/10.1016/j.pdpdt.2016.05.008.

* Corresponding author.

E-mail address: alessandra.keiko@gmail.com (A.K. Lima Fujita). 

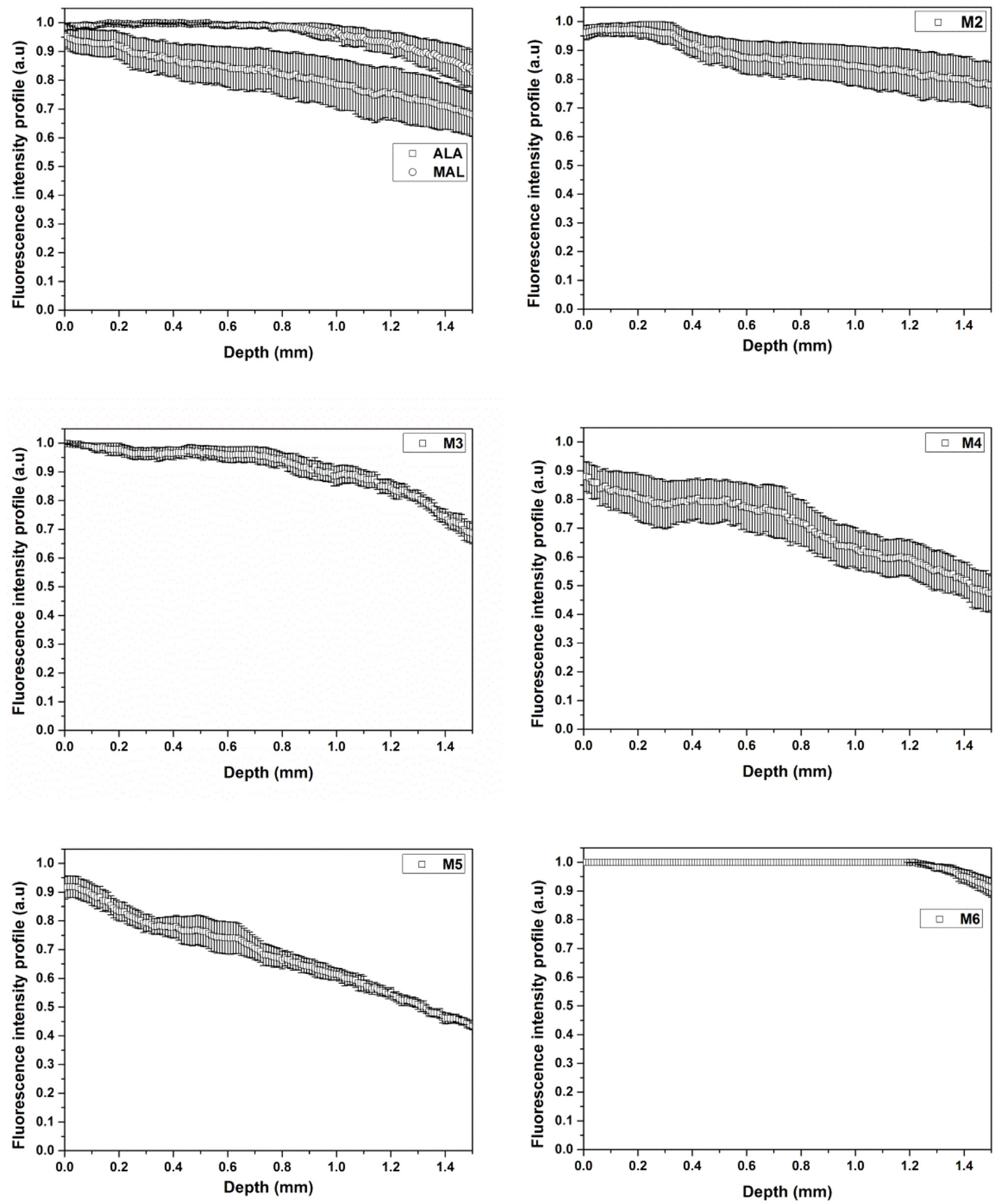